\title{
The Effect of Food Odor Exposure on Appetite and Nutritional Intake of Older Adults with Dementia
}

\author{
M.H. Verwijs ${ }^{1,2}$, O. van de Rest ${ }^{1}$, G.-J.van der Putten ${ }^{1,3}$, L.C.P.G.M. de Groot ${ }^{1, *}$, S. Boesveldt ${ }^{1, *}$
}

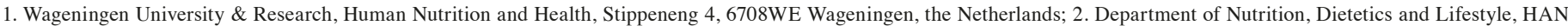

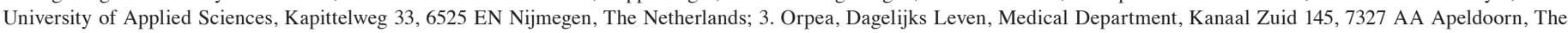
Netherlands; * Shared last authorship

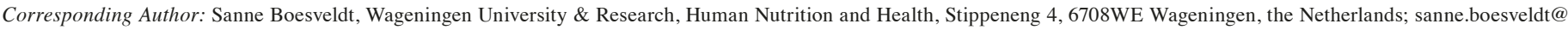
wur.nl

\begin{abstract}
OBJECTIVES: Dementia can lead to decreased appetite and nutritional intake. Food odor exposure has been shown to increase appetite and nutritional intake in young healthy adults. This study investigates the effect of food odor exposure on appetite, nutritional intake and body weight of Dutch nursing home residents with dementia.

DESIGN: This was a one-armed, non-randomized, non-blinded intervention study consisting of a four-week control period followed by a twelve-week intervention period.

SETTING: Four nursing homes in the Netherlands.

PARTICIPANTS: Forty-five nursing home residents with dementia.

INTERVENTION: During the intervention period, odors were dispersed prior to the main meals.

MEASUREMENTS: General and specific appetite for sweet and savory foods was measured weekly. Nutritional intake was measured once during the control period and three times during the intervention period through a 3-day food record. Body weight was assessed at the start and end of the control period and at the start, end and halfway the intervention period. Data were analyzed with linear mixed models.

RESULTS: Small changes in general and specific appetite were observed after odor exposure. Overall energy intake did not change during the first four intervention weeks, but increased during the second and third $(+118 \mathrm{kcal} / \mathrm{d}, \mathrm{p}=0.003$ and $+122 \mathrm{kcal} / \mathrm{d}, \mathrm{p}=0.004)$. Protein intake and body weight did not significantly change during the study.

CONCLUSION: In this study, no clinically relevant changes in appetite, nutritional intake and body weight were observed after food odor exposure. Future studies should assess the effect of natural food odors and/or meal-tailored odors on nutritional intake of older adults with dementia.
\end{abstract}

Key words: Olfaction, cognition, nutrition, dementia.

\section{Introduction}

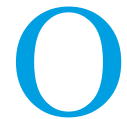

ver the past centuries, life expectancy of our world population has grown steadily. Although we can enjoy life for a longer period of time, aging is often accompanied by physical and/or mental decline (1-4). As a result of this age-related mental decline dementia may develop. Appetite of a patient with dementia often changes over the course of time $(5,6)$, and due to the decline in mental functioning, patients often forget to eat and drink (7). Consequently, malnutrition is frequently present among older adults with dementia (8).

Sensory cues, such as food odors, can increase appetite and influence food choice (9-11). An example from everyday life: when you walk past a bakery and smell their freshly baked bread, it triggers your appetite for it. Accordingly, studies among healthy adults showed that exposure to food odors enhances appetite for congruent foods, but not for other foods (9-13). For example, exposure to banana odor increased appetite for banana and other sweet foods, and likewise, participants who were exposed to a pear odor were more likely to choose fruity desserts compared to participants in the control condition $(11,12)$. Although appetite for specific foods is shown to increase after exposure to similar food odors, effects on subsequent dietary intake are inconsistent $(10,11,14$, 15). e.g., participants exposed to a chocolate odor more often chose and consumed sweet, high-energy foods compared to the control condition $(13,15)$. However, other studies showed no impact of food odor exposure on congruent preferences or intake $(14,16)$.

Previous studies investigating the effect of odor exposure on appetite and nutritional intake were mainly conducted in healthy younger adults (9-13). Thus far, only one study by Sulmont-Rossé et al. (2018) investigated the effect of (repeated) exposure to a meat odor prior to lunches on subsequent food intake in nursing home residents with dementia (17). After the first odor exposure, interest towards the meal enhanced and meat and vegetable intake increased with $25 \%$. However, no effects on interest towards the meal nor effects on food intake were shown after the second odor exposure.

Altogether, results from previous studies appear promising and dispersing odors through vaporizers would be a relatively simple way to increase appetite and nutritional intake in an older population that is at risk of malnutrition. Yet, most studies focused on short-term effects only, while long-term effects are more relevant for real-life application. Therefore, the aim of this study is to investigate the effect of a twelve-week food odor exposure on appetite, nutritional intake and body weight of older adults with dementia. 
Figure 1. Set-up of the study ( $\mathrm{C}=$ control period ( 4 weeks); $\mathrm{I} 1=$ First intervention block ( 4 weeks); $\mathrm{I} 2=$ second intervention block (4 weeks); I3 = third intervention block (4 weeks))

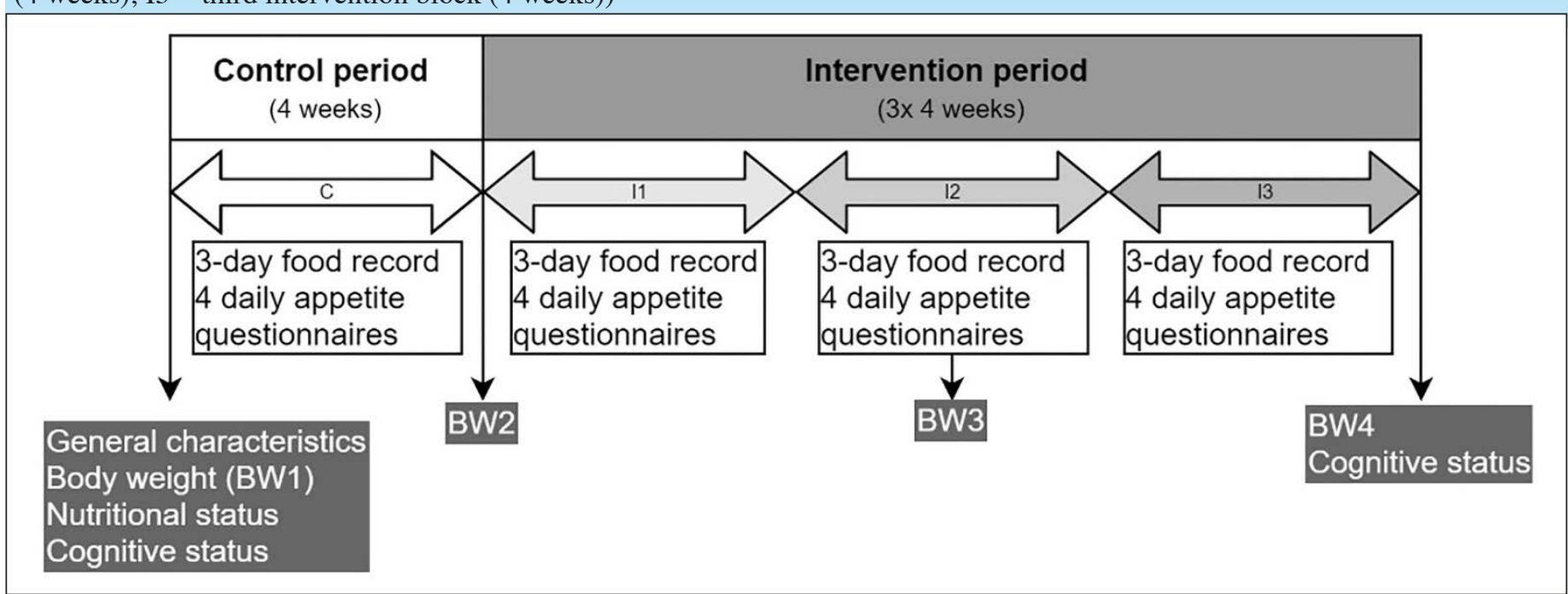

\section{Materials \& Methods}

\section{Participants}

Participants were recruited from psychogeriatric wards of four different nursing homes in the Netherlands, all part of the health care organization Amaris. Exclusion criteria were: aged $<65$ years, BMI $>35 \mathrm{~kg} / \mathrm{m}^{2}$, residing at a somatic or shortstay ward, in a terminal or vegetative stage, using (par)enteral nutrition or not being able to communicate about their appetite.

\section{Design}

This was a one-armed, non-randomized, non-blinded intervention study, consisting of a four week control period, followed by a twelve week intervention period in which odors were dispersed prior to breakfast, lunch and dinner. The twelve week intervention period consisted of three consecutive blocks of four weeks: I1; I2 and I3. Nutritional intake and appetite were measured during the four week control period and the three intervention blocks. Body weight was measured at the start of the control period (BW1) and at the end of the control/ beginning of the intervention period (BW2) and halfway (BW3) and at the end (BW4) of the intervention period.

In order to reduce any potential seasonal effect on nutritional intake, two nursing homes were included during spring and summer and two during fall and winter. The set-up of the study including all measurements that have been performed is depicted in figure 1 .

\section{Odors}

During the twelve week-intervention period odors were dispersed in the communal living rooms or private rooms of the participants, depending on where participants resided during the day. Odors were dispersed three times a day during a period of 30 minutes prior to meal consumption: a bread odor, a vegetable stock odor and a beef stew odor to match breakfast, lunch and dinner respectively. A pilot study among nine older adults was conducted to determine which odors were most pleasant, and best suited for (i.e. be congruent with food consumed during) breakfast, lunch and dinner. All odors were designed and produced by Iscent (Zeewolde, the Netherlands). Odors were dispersed using Iscent 400 vaporizers from the same company. The intensity of the odors was set to be clearly noticeable by healthy adults, therefore likely just noticeable by the participants.

\section{Measurements}

Most measurements were performed on or by the participants themselves. If this was not possible due to memory loss as a result of dementia, e.g. in the case of general characteristics, legal representatives or registered nurses were asked for assistance.

\section{General characteristics}

Before the start of the study, participant characteristics were recorded. The Dutch version of the Mini Nutritional Assessment Short-Form (MNA-SF) (19) and the Simplified Nutritional Appetite Questionnaire (SNAQ) (20) were administered to assess nutritional status and the risk of losing weight respectively. MNA-SF scores vary from $0-14$ : $0-7$ indicates undernutrition, 8-11 indicates a risk of undernutrition and scores $>11$ indicate a normal nutritional status. Outcomes of the SNAQ vary from $0-20$ : outcomes $<14$ indicates a significant risk of $\geq 5 \%$ body weight loss during the past 6 months. The Severe Impairment Battery (SIB-8) (21) was completed to give insight into participants' cognitive status. The SIB-8 is a non-invasive short questionnaire covering different domains of cognitive functioning. The higher the score on the SIB- 8 , the better the cognitive status, and vice versa. SIB- 8 was measured before the start and at the end of the study. 


\section{Appetite}

General and specific appetite was measured once a week right before breakfast, lunch and dinner during both control and intervention period. In total, appetite was measured four days during the control period and twelve days during the intervention period. Through a 5-point Likert scale (1 $=$ not at all; $2=$ not really; $3=$ neutral; $4=$ a bit; $5=$ very) participants were asked to indicate whether they were hungry (general appetite) and to what extent they would like to eat something sweet or something savory (specific appetite: sweet and savory). During the intervention period, the appetite questionnaire was completed after an odor exposure of at least 20 minutes. Data from these appetite ratings were aggregated into one mean per time block, calculated as a mean before breakfast, lunch and dinner, both for general and specific appetite for sweet and savory foods.

\section{Nutritional intake}

During the study, nutritional intake was monitored through four 3-day food records in total: one 3-day food record during each block of four weeks (control, I1, I2, I3). Research assistants completed the food records on three subsequent weekdays with the help of caregivers. Food records were entered into Compl-Eat, a program that calculates nutritional intake based on the NEVO-database on food composition (RIVM, 2016). Portion sizes of foods and drinks consumed during breakfast, lunch and in-between meals were entered into the food records by means of household measures and standardized portions. Soup, hot meals and desserts were weighed before serving. Possible leftovers were weighed and subtracted from the portion served. Data from the 3-day food records were aggregated into one mean per time block, calculated as a daily total for energy intake (kcal) and protein intake $(\mathrm{g})$.

\section{Body weight}

Body weight was measured in kilogram $(\mathrm{kg})$ at one decimal accuracy, without shoes or heavy clothing. Wheelchair scales with handrails were used that were available in the nursing homes. In order to calculate body weight, the weight of the wheelchair or walking aid was subtracted from the total weight.

\section{Data analysis}

\section{Sample size calculation}

Based on the appetite results of a study by Ramaekers et al. (2013) a sample size calculation was performed(9). Using a power of $80 \%$ and a two-sided significance level $(\alpha)$ of 0.05 the total required sample size would be 34 research subjects. Anticipating a drop-out rate of $\approx 20 \% 40$ research subjects in total would be needed to have sufficient research subjects.

\section{Analyses}

Descriptive statistics were performed and general characteristics are reported as means and standard deviations for continuous data and frequencies and percentages for categorical data. Linear mixed models (intention-to-treat) were performed to test for differences in appetite ratings, energy intake, protein intake, and body weight between control period and the three intervention blocks (I1, I2, I3). For all variables, a two-level structure was used to correct for clustering within the four measurements (Control, I1, I2, I3). Therefore, a random intercept was created at participant level. Time (control/I1/ I2/I3) was used as fixed-effect term. Covariates were added to the model when they were significantly correlated with the outcome variable. For energy and protein intake, Age and Height were added to the models as covariates. For body weight, Height was added to the model as a covariate. The outcome of the MNA-SF was added as a covariate in the models of savory appetite before breakfast, before dinner and to the daily total. For sweet and savory appetite before lunch, SIB-score was added to the model as a covariate. Post hoc comparisons (Least Significance Difference) were performed to compare main effects between the different time blocks (control/I1/I2/I3) for appetite ratings, energy intake, protein intake and body weight. Statistical analyses were performed using IBM SPSS Statistics version 25.0 (IBMCorp., Armonk, NY, USA) and a P-value below 0.05 was considered significant.

\section{Results}

\section{Participants}

Forty-five participants living in psychogeriatric wards of four nursing homes were recruited between March 2018 and September 2020. Participants were aged $72-98$ years $(88 \pm$ 6.2), 38 participants were female, and BMI ranged from 17.1 - $34.8 \mathrm{~kg} / \mathrm{m}^{2}\left(24.4 \pm 4.4 \mathrm{~kg} / \mathrm{m}^{2}\right)$. General characteristics of all participants are depicted in table 1 . There were no differences is general characteristics between residents of the four different nursing homes.

Thirty-two participants completed the study: two participants deceased, two participants were not able to finish the study due to physical deterioration and one participant moved to another nursing home during the study. Due to a renovation of the living rooms in one of the nursing homes, data of four participants were collected during fourteen weeks in total (ten weeks of intervention) and data of four other participants were collected during twelve weeks in total (eight weeks of intervention).

\section{Appetite}

\section{General appetite}

Mean general appetite scores ranged from 3.7 - 4.0 before breakfast, indicating a (little) bit hungry, and decreased significantly in I1 compared to the control period $(\mathrm{p}=0.037)$. 
However, general appetite before breakfast returned to baseline level of the control period in I3 $(\mathrm{p}=0.028)$. Mean general appetite scores before lunch ranged from $3.3-3.6$ and from 3.5 - 3.6 before dinner. No significant differences were found for general appetite before lunch and dinner between control and intervention period. Mean appetite scores $( \pm \mathrm{SE})$ are shown in figure $2 \mathrm{~A}$.

Table 1. General characteristics of participants in frequencies (percentages); mean values (SDs)

\begin{tabular}{|c|c|}
\hline & Total \\
\hline Participants (n) & 45 \\
\hline \multicolumn{2}{|l|}{ Age } \\
\hline Mean (SD) & $88.2(6.2)$ \\
\hline Range & $72-98$ \\
\hline \multicolumn{2}{|l|}{ Gender } \\
\hline Male & $7(15.6 \%)$ \\
\hline Female & $38(84.4 \%)$ \\
\hline \multicolumn{2}{|l|}{ BMI } \\
\hline Mean (SD) & $24.4(4.4)$ \\
\hline Range & $17.1-34.8$ \\
\hline \multicolumn{2}{|l|}{ Diagnosis } \\
\hline Alzheimer's disease & $20(44.4 \%)$ \\
\hline Vascular dementia & $9(20.0 \%$ \\
\hline Parkinson's disease related dementia & $3(6.7 \%)$ \\
\hline Combination of types & $6(13.3 \%)$ \\
\hline Undiagnosed & $7(15.6)$ \\
\hline \multicolumn{2}{|l|}{ MNA-SF } \\
\hline Mean (SD) & $9.4(2.3)$ \\
\hline Normal nutritional status (12-14p) & $7(15.6 \%)$ \\
\hline Risk on malnutrition (8-11p) & $30(66.7 \%)$ \\
\hline Malnourished (0-7p) & $8(17.8 \%)$ \\
\hline \multicolumn{2}{|l|}{ SNAQ } \\
\hline Mean (SD) & $15.4(2.1)$ \\
\hline No risk & $29(64.4 \%)$ \\
\hline Risk on $5 \%$ weight loss within 6 months $(<15 p)$ & $16(35.6 \%)$ \\
\hline \multicolumn{2}{|l|}{ SIB score } \\
\hline Mean (SD) & $13.4(8.9)$ \\
\hline Range & $0-32$ \\
\hline
\end{tabular}

\section{Appetite for sweet foods}

Appetite for sweet foods before breakfast ranged from $3.4-3.7$ and increased significantly between the first and second intervention block $(p=0.042)$. Appetite for sweet foods before lunch and dinner ranged from $2.8-3.0$ and $3.2-3.3$ respectively, but did not change significantly during the intervention period compared to the control period. Mean appetite scores $( \pm \mathrm{SE})$ are shown in figure $2 \mathrm{~B}$.

\section{Appetite for savory foods}

Mean appetite for savory foods before breakfast and lunch ranged from $3.1-3.2$ and $3.5-3.8$ respectively, but did not significantly change during the intervention period compared to the control period. Appetite for savory foods before dinner ranged from $3.5-3.9$ and increased significantly between the control period and the second $(\mathrm{p}=0.004)$ and third intervention block $(p=0.001)$. Mean appetite scores $( \pm S E)$ are shown in figure $2 \mathrm{C}$.

\section{Nutritional intake}

Mean energy intake ranged from $1362 \mathrm{kcal}$ to $1484 \mathrm{kcal}$ per day and mean protein intake ranged from 45.1 and $47.9 \mathrm{~g} / \mathrm{d}$ during the study. As shown in figure $3 \mathrm{~A}$, energy intake increased significantly during the second $(p=0.003)$ and third intervention block $(\mathrm{p}=0.004)$ compared to the first intervention block. The absolute difference in energy intake was approximately $118 \mathrm{kcal} / \mathrm{d}$ between I1 and I2 and $122 \mathrm{kcal} / \mathrm{d}$ between $\mathrm{I} 1$ and $\mathrm{I} 3$. In figure 3B, protein intake throughout the study is shown. There were no significant differences between control period and intervention period, nor between intervention blocks.

\section{Body weight}

Mean body weight $(\mathrm{kg})$ ranged from $65.6-66.7 \mathrm{~kg}$ but did not significantly change during the intervention period compared to the control period (figure 4). However, during the last six weeks of the intervention (I2), mean body weight tended to decrease with $1.1 \mathrm{~kg}(\mathrm{p}=0.058)$.

Mean appetite ratings, energy and protein intake and body weight $( \pm$ SEs $)$ are presented in Supplementary Table S1.

\section{Discussion}

The aim of this study was to investigate the effect of food odor exposure on appetite, nutritional intake and body weight of nursing home residents with dementia. The results of the present study show relatively small effects on general and specific appetite. Energy intake increased significantly during the second and third intervention block compared to the first intervention block, but not compared to the control condition. Protein intake and body weight were not significantly affected during the study. Despite careful consideration of the study design, few clinically relevant outcomes have been achieved during the intervention period. In the following paragraphs we elaborate on potential causes for the absence of clinically relevant outcomes and give recommendations for future research.

Previous studies found that olfactory function is generally impaired at a higher age $(24,25)$ and in patients with different types of dementia (26). As a result, participants in our study may not have been able to perceive the odors. Consequently, the effect size of the intervention may have increased when the intensity of the odors was adjusted to the olfactory function 
Figure 2. General appetite scores before breakfast, lunch and dinner in control versus intervention blocks (A); Appetite for sweet foods before breakfast, lunch and dinner in control versus intervention blocks (B); Appetite for savory foods before breakfast, lunch and dinner in control versus intervention blocks $(\mathrm{C})$; $\mathrm{n}$ is denoted in each bar

A Appetite before breakfast

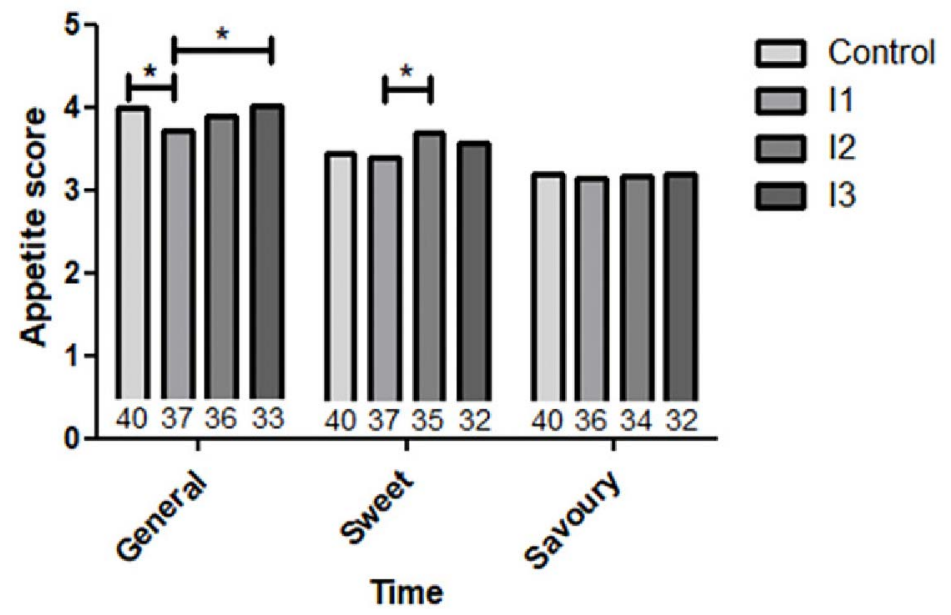

B Appetite before lunch

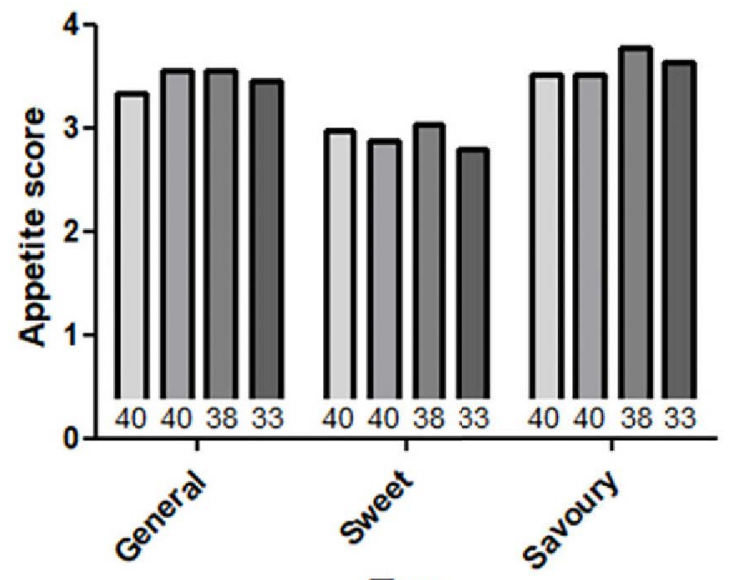

Time

C Appetite before dinner

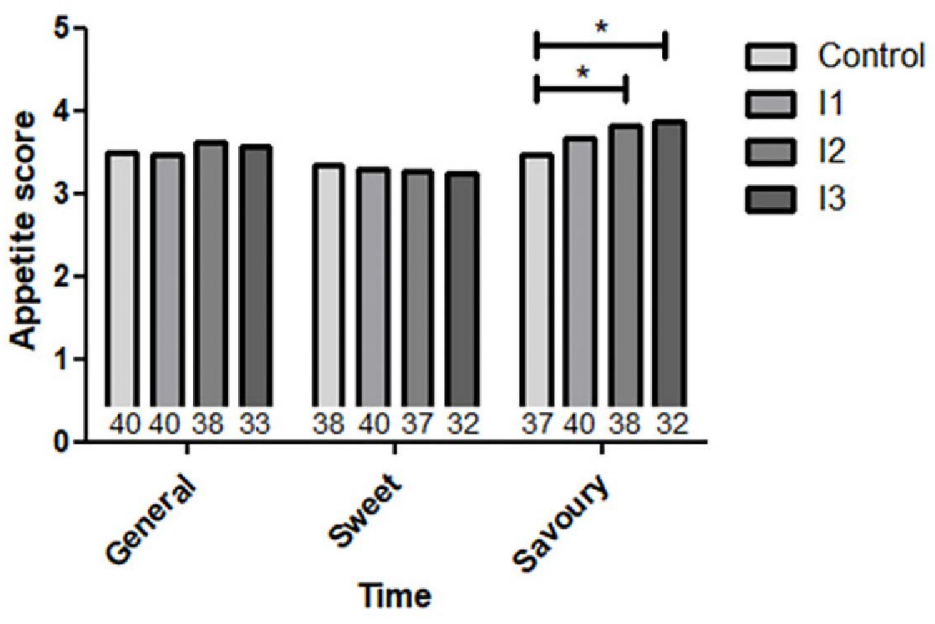

Figure 3. Daily energy intake in kcal during control period and intervention blocks (A); Daily protein intake in grams during control and intervention blocks (B). * indicates significant differences $(p<0.05)$; C n=45, I1 n=43, I2 n=42, I3 n=34
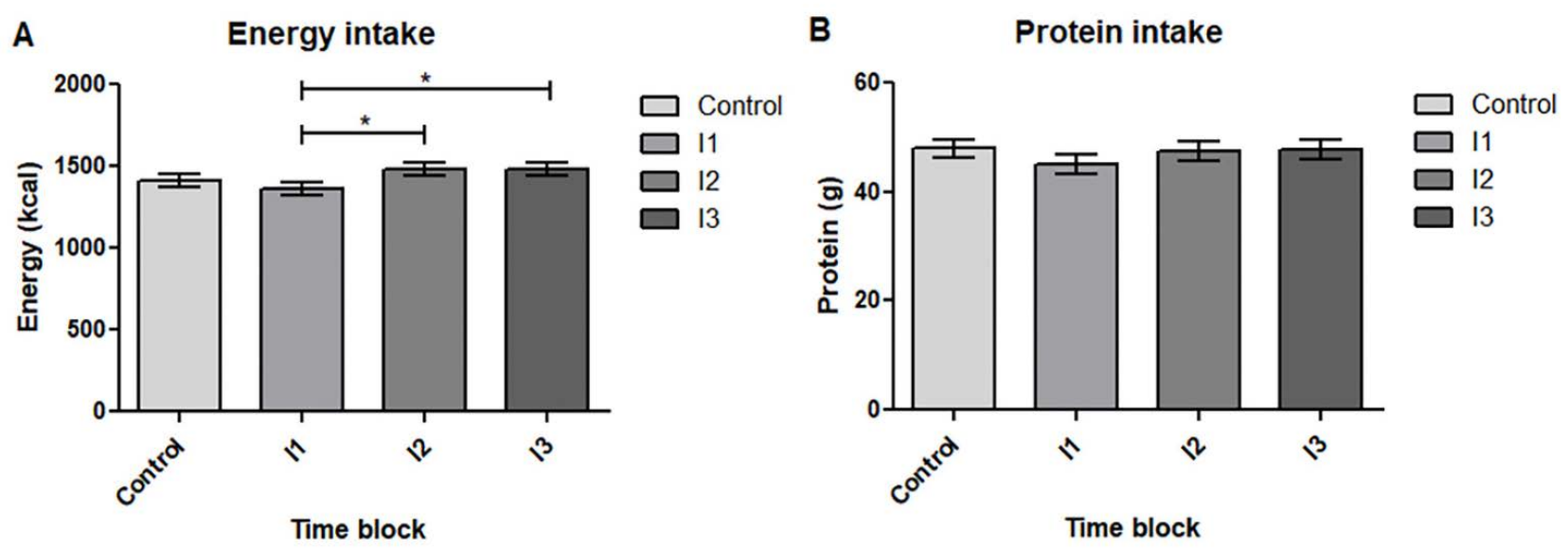
of individual participants instead of the general intensity maintained in the current study. However, a study by Doorduijn et al. (2020) showed that odor identification is often impaired in patients with dementia (27), while detection thresholds are similar to those of controls. Moreover, the concentration levels of the odors were set rather high, to ensure that all participants were able to detect the odors. Thus, participants in our study may have been able to detect the odors, but they may not have been able to correctly identify them.

Figure 4. Body weight at the start of the study (C1), after the control period/at the start of the intervention period (C2), halfway the intervention (I1) and at the end of the intervention (I2); $\mathrm{C} n=41, \mathrm{I} 1 \mathrm{n}=39, \mathrm{I} 2 \mathrm{n}=41, \mathrm{I} 3 \mathrm{n}=35$

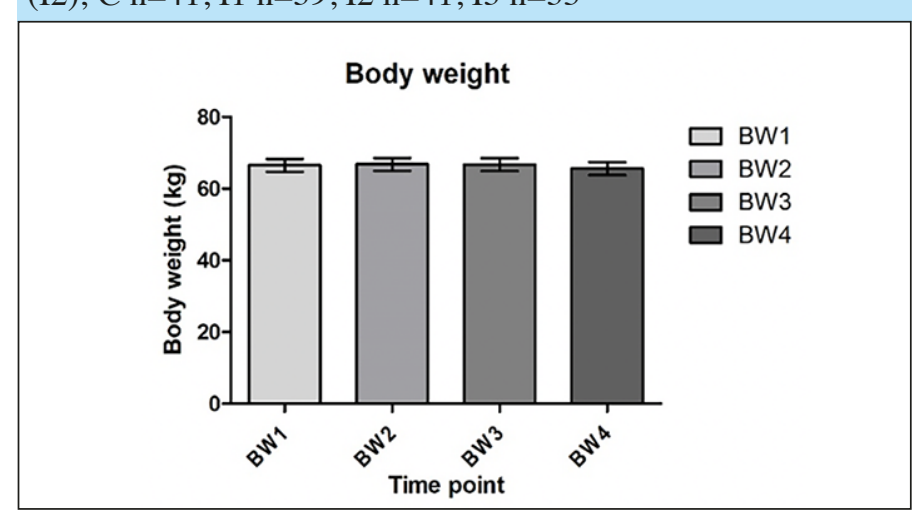

Furthermore, a study by Zoon et al. (2016) showed that odors signaling a sweet or savory taste led to an increased appetite for congruent foods(10). As meals were precooked and the menu varied throughout the year it is unlikely that the standard odors used in this study were congruent with all meals consumed subsequent to the odor exposure. In order to optimize the possible effect of food odor exposure on appetite and nutritional intake, future research should match the odors with the meal that is consumed subsequently. Therefore, it would be interesting to study the effect of natural food odors by preparing meals on site.

The absence of a significant effect of odor exposure on our three main outcomes may also be explained by the fact that three standard food odors were dispersed during the twelveweek intervention period, which may have led to olfactory habituation and adaptation (22). Köster et al. (2014) state that humans only respond to novel odors while little attention is paid to known odors (23). Similarly, in a study by Sulmont-Rossé et al. (2018) including older adults with dementia, the second exposure to a food odor did not show any effect on interest towards the meal and the actual meal consumed, while the first exposure to the same odor did positively affect both outcome measures (17). In our study, both appetite and food intake was measured throughout the total period of twelve weeks and not only during the first day of the odor exposure. Therefore, the novelty effect of the odors might have disappeared, showing no significant effect on the main outcomes of our study.

Even though the length of the 12-week intervention period and the fact that the study was performed in a real-life setting were major strengths of this study, the absence of a clinically relevant effect may be explained by the methods to measure these outcomes. Appetite was measured through a 5-point Likert scale. As older adults with dementia may experience difficulties in expressing their needs $(28,29)$, it is questionable whether the outcomes of the appetite ratings provide reliable outcomes. The method of assessing appetite was different in a study by Sulmont-Rossé et al. (17), i.e. through observations by the experimenters, therefore making it impossible to compare results. Therefore, future research is needed to investigate validity and feasibility of appetite ratings in older adults with dementia. Nutritional intake was measured through 3-day food records where nutritional intake was measured on weekdays by means of observations and by weighing soup, the hot meal and the dessert. This method is shown to be reliable in measuring intake in a population of institutionalized older adults (30) and provides more insights into the effects of food odor exposure on the diet compared to a single meal. However, mean energy intake during the control period (1410 kcal/day) was considerably lower compared to other studies observing nutritional intake in a population of nursing home residents diagnosed with dementia. Previous studies among nursing home residents with mild to severe dementia report an intake of 1650$1789 \mathrm{kcal}$ per day, measured through (weighed) food records $(28,29)$. This may indicate that energy intake in our population was lower compared to similar populations or that an error measurement has occurred, possibly due to portion estimation as not all meals were weighted. Further, it is recommended to include two weekdays and one weekend-day in a 3-day food record, as food consumption can differ during the weekend. However, in the nursing homes included in this study, there were hardly any differences in the food that was served during weekdays and weekend-days. Therefore, the effect of not including weekend-days should not have caused the large energy difference in our study compared to other studies. Finally, body weight decreased (but not significantly) during the last 6 weeks of the intervention $(-1.1 \mathrm{~kg}, \mathrm{p}=0.058)$. This is likely the result of an insufficient energy intake, as shown above, and underlines the urge for sustaining food intake in nursing home residents to prevent malnutrition.

\section{Conclusion}

In conclusion, the results of this study show no clinically relevant effects of food odor exposure on appetite, nutritional intake and body weight of nursing home residents with dementia. Future research should focus on optimizing odors and to validate appetite measurements in this specific population. In this way, further evidence will show whether food odor exposure increases appetite and nutritional intake in older adults with dementia.

Acknowledgements: We want to show our gratitude to all participants for participating in this study. Also, we would like to thank the caregivers and managers from Amaris for their efforts in completing this study. Last but not least, we would like to thank all research assistants for their help with collecting the data: Charlotte Kramer - Pam Bruijnen - Tessa Fris - Edith Leito - Joske van Schijndel - Pim Lenderink - Annika de Groot - Maudy Khouw - Emma Schouten - Bas van Buitenen - Annelie Groothuis - Rianne Halsberghe Dieuwertje Janssen - Tanja Küller

\section{Disclosure Statement: The authors report no conflicts of interest.}

Funding: This work was supported by Mr. Roelsefonds, grant numbers 2017-06, 2019 
Ethical standards: Most residents were incapacitated and therefore legal representatives approved participation in the study by signing informed consent. The study was conducted according to the principles of the Declaration of Helsinki (version 2013) and in accordance with the Medical Research Involving Human Participants Act (WMO). This study was approved by the Medical Ethical Committee of Wageningen University (NL64189.081.18).

Open Access: This article is distributed under the terms of the Creative Commons Attribution 4.0 International License (http://creativecommons.org/licenses/by/4.0/), which permits use, duplication, adaptation, distribution and reproduction in any medium or format, as long as you give appropriate credit to the original author(s) and the source provide a link to the Creative Commons license and indicate if changes were made.

\section{References}

1. Andersen FK, Christensen K, Frederiksen H. Self-rated health and age: A crosssectional and longitudinal study of 11,000 Danes aged 45-102. Scand J Public Health 2007:35:164-171. https://doi.org/10.1080/14034940600975674

2. Vestergaard S, Thinggaard M, Jeune B, Vaupel JW, McGue M, Christensen K. Physical and mental decline and yet rather happy? A study of Danes aged 45 and older. Aging Ment Heal 2015;19:400-408. https://doi.org/10.1080/13607863.2014.944089

3. Harada CN, Natelson Love MC, Triebel KL. Normal cognitive aging. Clin Geriatr Med 2013;29:737-752. https://doi.org/10.1016/j.cger.2013.07.002

4. Reichman WE, Fiocco AJ, Rose NS. Exercising the brain to avoid cognitive decline: Examining the evidence. Aging health 2010;6:565-584. https://doi.org/10.2217/ ahe. 10.54

5. Kuroda A, Setoguchi M, Uchino Y, Nagata K, Hokonohara D. Effect of rivastigmine on plasma butyrylcholine esterase activity and plasma ghrelin levels in patients with dementia in Alzheimer's disease. Geriatr Gerontol Int 2018;18:886-891. https://doi. org/10.1111/ggi.13275

6. Mitchell SL, Teno JM, Kiely DK, Shaffer ML, Jones RN, Prigerson HG, Volicer L, Givens JL, Hamel MB. The Clinical Course of Advanced Dementia. N Engl J Med 2009;361:1529-1538. https://doi.org/10.1056/NEJMoa0902234

7. Abdelhamid A, Bunn D, Copley M, Cowap V, Dickinson A, Gray L, Howe A, Killet A, Lee J, Li F, Poland F, Potter J, Richardson K, Smithard D, Fox C, Hooper L. Effectiveness of interventions to directly support food and drink intake in people with dementia: Systematic review and meta-analysis. BMC Geriatr 2016;16:26. https://doi. org/10.1186/s12877-016-0196-3

8. Camina Martín MA, Barrera Ortega S, Domínguez Rodríguez L, Couceiro Muiño C, de Mateo Silleras B, Redondo del Río MP. Presence of malnutrition and risk of malnutrition in institutionalized elderly with dementia according to the type and deterioration stage. Nutr Hosp 2012;27:434-440. https://doi.org/10.1590/s021216112012000200013

9. Ramaekers MG, Boesveldt S, Lakemond CMM, Van Boekel MAJS, Luning PA Odors: Appetizing or satiating Development of appetite during odor exposure over time. Int J Obes 2014;38:650-656. https://doi.org/10.1038/ijo.2013.143

10. Zoon H, de Graaf C, Boesveldt S. Food Odours Direct Specific Appetite. Foods 2016;5:12. https://doi.org/10.3390/foods5010012

11. Gaillet-Torrent M, Sulmont-Rossé C, Issanchou S, Chabanet C, Chambaron S Impact of a non-attentively perceived odour on subsequent food choices. Appetite 2014;76:17-22. https://doi.org/10.1016/j.appet.2014.01.009

12. Ramaekers MG, Boesveldt S, Gort G, Lakemond CMM, van Boekel MAJS, Luning PA. Sensory-Specific Appetite Is Affected by Actively Smelled Food Odors and Remains Stable Over Time in Normal-Weight Women. J Nutr 2014;144:1314-1319. https://doi.org/10.3945/jn.114.192567

13. Proserpio C, de Graaf C, Laureati M, Pagliarini E, Boesveldt S. Impact of ambient odors on food intake, saliva production and appetite ratings. Physiol Behav 2017;174:35-41. https://doi.org/10.1016/j.physbeh.2017.02.042

14. Morquecho-Campos P, de Graaf K, Boesveldt S. Smelling our appetite? The influence of food odors on congruent appetite, food preferences and intake. Food Qual Prefer 2020;85:103959. https://doi.org/10.1016/j.foodqual.2020.103959
15. Chambaron S, Chisin Q, Chabanet C, Issanchou S, Brand G. Impact of olfactory and auditory priming on the attraction to foods with high energy density. Appetite 2015;95:74-80. https://doi.org/10.1016/j.appet.2015.06.012

16. Zoon HFA, He W, de Wijk RA, de Graaf C, Boesveldt S. Food preference and intake in response to ambient odours in overweight and normal-weight females. Physiol Behav 2014;133:190-196. https://doi.org/10.1016/j.physbeh.2014.05.026

17. Sulmont-Rossé C, Gaillet M, Raclot C, Duclos M, Servelle M, Chambaron S. Impact of Olfactory Priming on Food Intake in an Alzheimer's Disease Unit. J Alzheimer's Dis 2018;66:1497-1506. https://doi.org/10.3233/JAD-180465

18. Ramaekers MG, Boesveldt S, Lakemond CMM, van Boekel MAJS, Luning PA. Odors: appetizing or satiating? Development of appetite during odor exposure over time. Int J Obes 2014;38:650-656. https://doi.org/10.1038/ijo.2013.143

19. Kaiser MJ, Bauer JM, Ramsch C, Uter W, Guigoz Y, Cederholm T, Thomas DR, Anthony P, Charlton KE, Maggio M, Tsai AC, Grathwohl D, Vellas B, Sieber CC. Validation of the Mini Nutritional Assessment short-form (MNA®-SF): A practical tool for identification of nutritional status. J Nutr Heal Aging 2009;13:782-788. https://doi.org/10.1007/s12603-009-0214-7

20. Wilson M-MG, Thomas DR, Rubenstein LZ, Chibnall JT, Anderson S, Baxi A, Diebold MR, Morley JE. Appetite assessment: simple appetite questionnaire predicts weight loss in community-dwelling adults and nursing home residents. Am J Clin Nutr 2005;82:1074-1081. https://doi.org/10.1093/ajen/82.5.1074

21. Schmitt FA, Saxton JA, Xu Y, McRae T, Sun Y, Richardson S, Li H. A Brief Instrument to Assess Treatment Response in the Patient With Advanced Alzheimer Disease. Alzheimer Dis Assoc Disord 2009;23:377-383. https://doi.org/10.1097/ WAD.0b013e3181ac9cc1

22. Pellegrino R, Sinding C, de Wijk RA, Hummel T. Habituation and adaptation to odors in humans. Physiol Behav 2017;177:13-19. https://doi.org/10.1016/j. physbeh.2017.04.006

23. Köster EP, Møller P, Mojet J. A "Misfit" Theory of Spontaneous Conscious Odor Perception (MITSCOP): reflections on the role and function of odor memory in everyday life. Front Psychol 2014;0:64. https://doi.org/10.3389/fpsyg.2014.00064

24. Toussaint N, de Roon M, van Campen JPCM, Kremer S, Boesveldt S. Loss of Olfactory Function and Nutritional Status in Vital Older Adults and Geriatric Patients. Chem Senses 2015;40:197-203. https://doi.org/10.1093/chemse/bju113

25. Schubert CR, Cruickshanks KJ, Fischer ME, Huang G-H, Klein BEK, Klein R, Pankow JS, Nondahl DM. Olfactory Impairment in an Adult Population: The Beaver Dam Offspring Study. Chem Senses 2012;37:325-334. https://doi.org/10.1093/ chemse/bjr102

26. Albers MW, Tabert MH, Devanand DP. Olfactory Dysfunction As a Predictor of Neurodegenerative Disease, 2006. https://doi.org/10.1007/s11910-996-0018-7

27. Doorduijn AS, de van der Schueren MAE, van de Rest O, de Leeuw FA, Fieldhouse JLP, Kester MI, Teunissen CE, Scheltens P, van der Flier WM, Visser M, Boesveldt S. Olfactory and gustatory functioning and food preferences of patients with Alzheimer's disease and mild cognitive impairment compared to controls: the NUDAD project. J Neurol 2020;267:144-152. https://doi.org/10.1007/s00415-019-09561-0

28. Murphy J, Holmes J, Brooks C. Measurements of daily energy intake and total energy expenditure in people with dementia in care homes: The use of wearable technology. J Nutr Heal Aging 2017;21:927-932. https://doi.org/10.1007/s12603-017-0870-y

29. Salminen KS, Suominen MH, Kautiainen H, Roitto HM, Pitkala KH. Energy intake and severity of dementia are both associated with health-related quality of life among older long-term care residents. Nutrients 2019;11:2261. https://doi.org/10.3390/ nu11102261

30. de Vries JHM, de Groot LCPGM, van Staveren WA. Dietary assessment in elderly people: Experiences gained from studies in the Netherlands. Eur J Clin Nut 2009;63:S69-S74. https://doi.org/10.1038/ejen.2008.68

How to cite this article: M.H. Verwijs, O. van de Rest, G.-J. van der Putten, et al. The Effect of Food Odor Exposure on Appetite and Nutritional Intake of Older Adults with Dementia. J Nutr Health Aging. 2022;26(2):112-118, http://dx.doi.org/10.1007/s12603$021-1719-y$ 